\title{
Exercise Improves Glucose Disposal and Insulin Signaling in Pregnant Mice Fed a High Fat Diet
}

\author{
Lindsay G Carter ${ }^{1}$, Sara Y Ngo Tenlep', Laura A Woollett ${ }^{2}$ and Kevin J Pearson ${ }^{1 *}$ \\ ${ }^{1}$ Pharmacology and Nutritional Sciences, College of Medicine, University of Kentucky, 900 South Limestone, Lexington, KY 40536-0200, USA \\ ${ }^{2}$ Department of Pathology and Laboratory Medicine, Medical Diseases Institute, University of Cincinnati Medical School, 2180 East Galbraith Rd, Cincinnati, OH 45237-
} 0507, USA

\begin{abstract}
Objective: Physical activity has been suggested as a non-pharmacological intervention that can be used to improve glucose homeostasis in women with gestational diabetes mellitus. The purpose of this study was to determine the effects of voluntary exercise on glucose tolerance and body composition in pregnant high fat diet fed mice.

Methods: Female mice were put on a standard diet or high fat diet for two weeks. The mice were then split into 4 groups; control standard diet fed, exercise standard diet fed, control high fat diet fed, and exercise high fat diet fed. Exercise mice had voluntary access to a running wheel in their home cage one week prior to mating, during mating, and throughout pregnancy. Glucose tolerance and body composition were measured during pregnancy. Akt levels were quantified in skeletal muscle and adipose tissue isolated from saline or insulin injected pregnant dams as a marker for insulin signaling.
\end{abstract}

Results: Consumption of the high fat diet led to significantly increased body weight, fat mass, and impaired glucose tolerance in control mice. However, voluntary running in the high fat diet fed dams significantly reduced weight gain and fat mass and ultimately improved glucose tolerance compared to control high fat diet fed dams. Further, body weight, fat mass, and glucose disposal in exercise high fat diet dams were indistinguishable from control dams fed the standard diet. High fat diet fed exercise dams also had significantly increased insulin stimulated phosphorylated Akt expression in adipose tissue, but not skeletal muscle, compared to control dams on high fat diet.

Conclusion: The use of voluntary exercise improves glucose homeostasis and body composition in pregnant female mice. Thus, future studies could investigate potential long-term health benefits in offspring born to obese exercising dams.

Keywords: Obesity; Running; Gestation; Intervention; Glucose intolerance; Metabolism; Voluntary exercise

\section{Introduction}

Gestational diabetes mellitus (GDM) is defined as glucose intolerance first recognized during pregnancy, and women diagnosed with GDM have a $35-60 \%$ chance of developing type 2 diabetes mellitus (T2DM) within 10 to 20 years postpartum [1,2]. Recently, the number of women with GDM have been increasing with approximately $2-8 \%$ of pregnancies in the U.S. affected by GDM [3,4]. Though a natural insulin resistance develops to ensure adequate glucose supply to the fetus in all pregnancies, this further develops into GDM in some women, especially those who are obese [5,6]. Babies born to diabetic mothers are also at risk for metabolic disorders. In Pima Indians, a well-studied population known to have high rates of T2DM and GDM, offspring exposed to diabetes during gestation have a higher incidence of obesity and T2DM later in life $[7,8]$. In another human study, it was found that high gestational glucose concentration is positively correlated with insulin resistance in offspring at approximately 7 years of age [9]. An animal model of GDM also showed higher body weights and impaired glucose regulation in offspring exposed to diabetes during gestation compared to offspring from non - obese, control dams [10]. Many other studies have found similar results [11-13].

There are many risk factors that enhance a woman's risk for developing GDM. Some of the factors are non-modifiable and thus cannot be changed, including age, ethnicity, and family history of diabetes $[14,15]$. There are, however, modifiable risk factors that can be targeted to help prevent GDM including body mass index, diet, and physical activity $[16,17]$. Since traditional medications used to treat diabetes such as insulin or oral drugs used to improve insulin sensitivity can potentially be harmful to the fetus, it is important to look at the modifiable risk factors as treatment options.

A few human studies have been conducted to investigate physical activity and the risk and management of GDM. Liu et al. [18] have shown that physical activity during pregnancy can reduce the incidence of GDM. Moderate exercise also can reduce the need for other treatments such as insulin in women with GDM $[19,20]$. In contrast, a recent randomized control trial has found that exercise during pregnancy did not reduce the risk of developing GDM [21]. In non-pregnant women, exercise is known to improve glucose uptake by increasing insulin sensitivity as well as stimulating non-insulin dependent glucose uptake in skeletal muscle. However, the effects of exercise on insulin sensitivity and insulin independent glucose uptake in pregnant women as well as

*Corresponding author: Kevin $\mathrm{J}$ Pearson, Pharmacology and Nutritional Sciences, College of Medicine, Wethington Room 591, University of Kentucky, 900 South Limestone, Lexington, KY 40536-0200, USA, Tel: 859-218-1371; Fax : 859-257-3646; E-mail: kevin.pearson@uky.edu

Received November 16, 2015; Accepted December 28, 2015; Published December 30, 2015

Citation: Carter LG, Tenlep SYN, Woollett LA, Pearson KJ (2015) Exercise Improves Glucose Disposal and Insulin Signaling in Pregnant Mice Fed a High Fat Diet. J Diabetes Metab 6: 634. doi:10.4172/2155-6156.1000634

Copyright: ( 2015 Carter LG, et al. This is an open-access article distributed unde the terms of the Creative Commons Attribution License, which permits unrestricted use, distribution, and reproduction in any medium, provided the original author and source are credited. 
potential offspring benefits of maternal exercise have not been studied to the same extent. This makes research focusing on these pathways in pregnant women necessary. For example, Hopkins et al. [22] have shown that exercise during pregnancy does not improve maternal insulin sensitivity but still impacts offspring birth weight.

Despite the promising results observed in human studies, it is necessary to study maternal and offspring effects of exercise during pregnancy in animals models as they allow for more extensive research to be performed, including elucidating tissue specific mechanisms. The purpose of this study was to test our hypothesis that exercise prior to and during pregnancy would improve obesity and glucose tolerance outcomes in female high fat diet (HFD) fed pregnant mice.

\section{Materials and Methods}

\section{Animals and diets}

Studies conducted at the University of Kentucky were approved by the Institutional Animal Care and Use Committee. Sixty female primiparous Institute for Cancer (ICR) mice were ordered from Taconic (Hudson, NY) after delivering one litter prior to their arrival at the University of Kentucky at $\sim 4$ months of age. Females were housed 4 per cage for a 2 week acclimation period following their arrival. Mice were housed in an environmentally controlled vivarium with temperature ranging from $68-72^{\circ} \mathrm{F}$ and a 14 hour light/10 hour dark cycle. After acclimation, females were individually housed for the remainder of the study. Females were placed on either a semipurified standard diet (SD) $(14.6 \% \mathrm{kcal}$ diet from fat; Mod TestDiet 5342 5SSG) or HFD (40.5\% kcal diet from fat; Mod TestDiet 5342 5SSH). The HFD also contained higher levels of sucrose, salt, and cholesterol. More detailed diet information is available in (Table 1). Females had unlimited access to food and water. After 2 weeks on the diets, females were randomly separated into 4 groups; control $\mathrm{SD}$, exercise SD, control HFD, and exercise HFD. There were no

\begin{tabular}{|c|c|c|c|}
\hline \multicolumn{2}{|c|}{$\begin{array}{c}\text { Standard diet (Mod TestDiet }{ }^{\circledR} 5342 \\
\text { 5SSG) }\end{array}$} & \multicolumn{2}{|c|}{$\begin{array}{c}\text { High fat diet } \text { (Mod TestDiet }{ }^{\circledast} 5342 \\
\text { 5SSH) }\end{array}$} \\
\hline Ingredient & $\%$ & Ingredient & $\%$ \\
\hline Corn starch & 26.5507 & Corn starch & 4.9923 \\
\hline Dextrin & 25.0000 & Sucrose & 31.2186 \\
\hline Casein & 21.3567 & Casein & 21.6017 \\
\hline Maltodextrin & 9.9846 & Maltodextrin & 9.9846 \\
\hline Milk fat & 5.4023 & Milk fat & 19.9692 \\
\hline Powered cellulose & 4.9923 & Powered cellulose & 4.9923 \\
\hline AIN - 76 mineral mix & 3.4946 & AIN - 76 mineral mix & 3.4946 \\
\hline AIN - 76 vitamin mix & 0.9985 & AIN - 76 vitamin mix & 0.9985 \\
\hline Corn oil & 0.9985 & Corn oil & 0.9985 \\
\hline Calcium carbonate & 0.3994 & Calcium carbonate & 0.3994 \\
\hline Salt & 0.3068 & Salt & 0.6973 \\
\hline $\mathrm{DL}$ - methionine & 0.2995 & $\mathrm{DL}$ - methionine & 0.2995 \\
\hline Choline bitartrate & 0.1997 & Choline bitartrate & 0.1997 \\
\hline Cholesterol & 0.0097 & Cholesterol & 0.1498 \\
\hline $\begin{array}{l}\text { Ethoxyquin } \\
\text { (preservative) }\end{array}$ & 0.0040 & $\begin{array}{l}\text { Ethoxyquin } \\
\text { (preservative) }\end{array}$ & 0.0040 \\
\hline \multirow[t]{2}{*}{ Vitamin A palmitate* } & 0.0018 & - & - \\
\hline & $\mathrm{kcal} / \mathrm{g}$ kcal\% & & kcal/g kcal\% \\
\hline Fat & $0.558 \quad 14.6$ & Fat & $1.804 \quad 40.5$ \\
\hline Protein & $0.772 \quad 20.2$ & Protein & $0.772 \quad 17.3$ \\
\hline Carbohydrate & $2.495 \quad 65.2$ & Carbohydrate & 1.88242 .2 \\
\hline
\end{tabular}

*The diet supplier notes that milk fat contains vitamin A; therefore vitamin A was added to the SD to match the amount found in the HFD.

Table 1: Maternal diets used in the study. initial weight differences between the 4 groups. Mice in the exercise cohorts were housed in cages with voluntary access to a running wheel (Phenome Technologies, Inc. Lincolnshire, IL) mounted in the cage for 1 week prior to mating, during mating, and during gestation. Running distance per day was monitored for the duration of the study using a magnetic counter (Clock Lab software, Actimetrics, Wilmette, IL). Control females were housed in identical cages that did not contain a running wheel. After 1 week in the control or exercise groups, male ICR mice were introduced into the female cage for mating. After 4 days, males were removed and female mice that did not conceive were removed from the study. During all portions of the study, female body weight and food intake were monitored weekly. Energy intake per day was calculated by dividing the weekly food intake values by 7 days as a measure of daily food intake and then multiplying by the number of $\mathrm{kcal} / \mathrm{g}$. To determine food intake while males were in the cage, food intake was divided by 2 to account for both mice. Due to mating over the course of 4 days, gestation days were estimated such that day 0 corresponds to first day of mating. Females that did not gain weight within 14 days were removed from the study as they were not pregnant.

\section{Glucose tolerance testing}

Glucose tolerance was measured in female mice prior to mating after 2 weeks of HFD feeding and in dams at gestation day $\sim 14$ Mice were fasted for 3 hours then given an intraperitoneal injection of D-(+)-glucose (Sigma-Aldrich, St. Louis, MO) at $2 \mathrm{~g}$ per $\mathrm{kg}$ body weight. Glucose levels were measured in whole blood using an Ascensia Breeze 2 meter (Bayer, Mishawaka, IN) following a tail vein prick prior to injection $(0 \mathrm{~min})$ and $15,30,60$, and 120 min post - injection.

\section{Body composition analysis}

Body composition was analyzed in live, pregnant mice at gestation day 17 using nuclear magnetic resonance (EchoMRI; EchoMedical Systems; Houston, TX). The EchoMRI measures adipose tissue, lean mass, and free and total water. Although many tissues contribute to the lean mass output, there are undetectable components such as bone mineral content, hair, and claws.

\section{Western blot analysis}

Western blotting was used to analyze total and phosphorylated Akt levels in adipose (parametrial) and skeletal muscle (soleus) tissue excised from pregnant mice at gestation day 18. Dams on the HFD were fasted $3 \mathrm{~h}$ and injected with saline or porcine insulin (Sigma, I-5523) at $1.25 \mathrm{IU} / \mathrm{kg}$ body weight. Fifteen min later, mice were euthanized and tissues were collected. Total and phosphorylated Akt (serine 473) primary antibodies were purchased from Cell Signaling Technology (\#4685 and \#4058, respectively). Peroxidase conjugated immunoglobulin $\mathrm{G}$ secondary antibody was ordered from Millipore (Billerica, MA) (goat anti - rabbit \#AP132P). Tissues were homogenized in cell lysis buffer and a Bradford assay was used to determine sample protein concentrations. For western blots, $12 \mu \mathrm{g}$ of protein was loaded onto a $4-20 \%$ gradient SDS - PAGE gel for separation. Protein was transferred to nitrocellulose membranes which were then incubated in primary antibody overnight at $4^{\circ} \mathrm{C}(1: 1000$ for total Akt and phosphorylated Akt). Membranes were washed then incubated in the secondary antibody (1:5000) for 1 hour then washed again. Bands were imaged using enhanced chemiluminescence detection reagents (FEMTOMAX - 110, Rockland, Gilbertsville, PA) using a BioRad ChemiDoc system. Intensity of bands was determined using Quantity One Analysis Software version 4.6.1 (BioRad, Hercules, CA). Data are represented as basal and insulin stimulated phosphorylation as a ratio of phosphorylated Akt to total Akt. 


\section{Statistical analysis}

For comparisons between 3 or more groups, a one-way ANOVA was performed followed by Fisher LSD post-hoc analysis. Student's t tests were used for comparisons between 2 groups. These analyses were performed using Sigma Plot 11.0 software (Systat, Point Richmond, CA). Data that failed the Shapiro-Wilk normality test was transformed by calculating the natural log of the values. Area under the curve (AUC) for blood glucose levels were calculated using "Area Below Curves" function in Sigma Plot 11.0.

\section{Results}

\section{Non-pregnant female body weight and glucose tolerance}

After 7 and 14 days of dietary treatment, Figure 1A shows mice on the HFD had significantly increased body weight compared to mice on the $\mathrm{SD}(\mathrm{P}=0.013$ and $\mathrm{P}<0.001$, respectively). A glucose tolerance test (Figure 1B) showed that female HFD fed mice had significantly impaired glucose disposal at 15, 30, 60, and 120 min post - injection compared to female mice fed the $\mathrm{SD}(\mathrm{P}=0.027, \mathrm{P}<0.001, \mathrm{P}<0.001$, and $\mathrm{P}=0.002$, respectively). AUC of blood glucose levels during the glucose tolerance test was also significantly increased in mice on HFD compared to those fed SD $(\mathrm{P}<0.001)$ (Figure 1C).

\section{Body weights and energy intake in female mice that became pregnant}

One week of voluntary running significantly decreased body weight in HFD fed mice compared to HFD fed controls $(\mathrm{P}=0.010)$, while control HFD mice weighed significantly more compared to control mice on SD $(\mathrm{P}<0.001)$ (Figure $2 \mathrm{~A})$. Females were placed with males for breeding on day 0 . After conception on days 7,14 , and 18 , HFD fed control dams weighed significantly more than control dams on SD $(\mathrm{P}=0.002, \mathrm{P}<0.001$, and $\mathrm{P}=0.017$, respectively). Exercise attenuated the weight gain in the HFD fed dams at days 7 and $14(\mathrm{P}$ $=0.008$ and $\mathrm{P}=0.011$, respectively) while toward the end of gestation at day 18 body weight differences between these two groups became insignificant $(P=0.337)$. Mean energy intake per day per mouse was significantly increased in control and exercise HFD dams compared to control dams on $\mathrm{SD}(\mathrm{P}<0.001$ and $\mathrm{P}=0.001$, respectively) (Figure $2 \mathrm{~B})$. However, there were no differences in caloric intake between control or exercising HFD fed dams.

\section{Pregnant female glucose tolerance}

During mid-gestation, a glucose tolerance test was performed in the pregnant dams. Exercise in the SD fed dams decreased blood glucose levels at 30 min post glucose injection compared to SD control dams ( $\mathrm{P}$ $=0.041$ ) (Figure $2 \mathrm{C}$ ). HFD fed control dams had significantly increased blood glucose levels compared to SD fed control dams at 60 and 120 min post glucose injection ( $\mathrm{P}=0.003$ and $\mathrm{P}=0.001$, respectively). Exercise in the HFD fed dams attenuated these increases in blood glucose at 60 and 120 min post glucose injection $(\mathrm{P}=0.027$ and $\mathrm{P}=$ 0.011 , respectively) such that these values did not differ from control $\mathrm{SD}$ fed dams. Control dams on HFD had significantly increased AUC of blood glucose levels compared to SD fed control dams $(\mathrm{P}=0.007)$ (Figure 2D) while AUC for exercise HFD dams did not significantly differ from control SD dams but was significantly decreased when compared to control HFD dams $(\mathrm{P}=0.049)$. These data suggest that exercise during pregnancy can protect against impaired glucose disposal caused by HFD consumption.

\section{Pregnant female body composition}

Body composition was measured late in pregnancy, and there

\section{A}
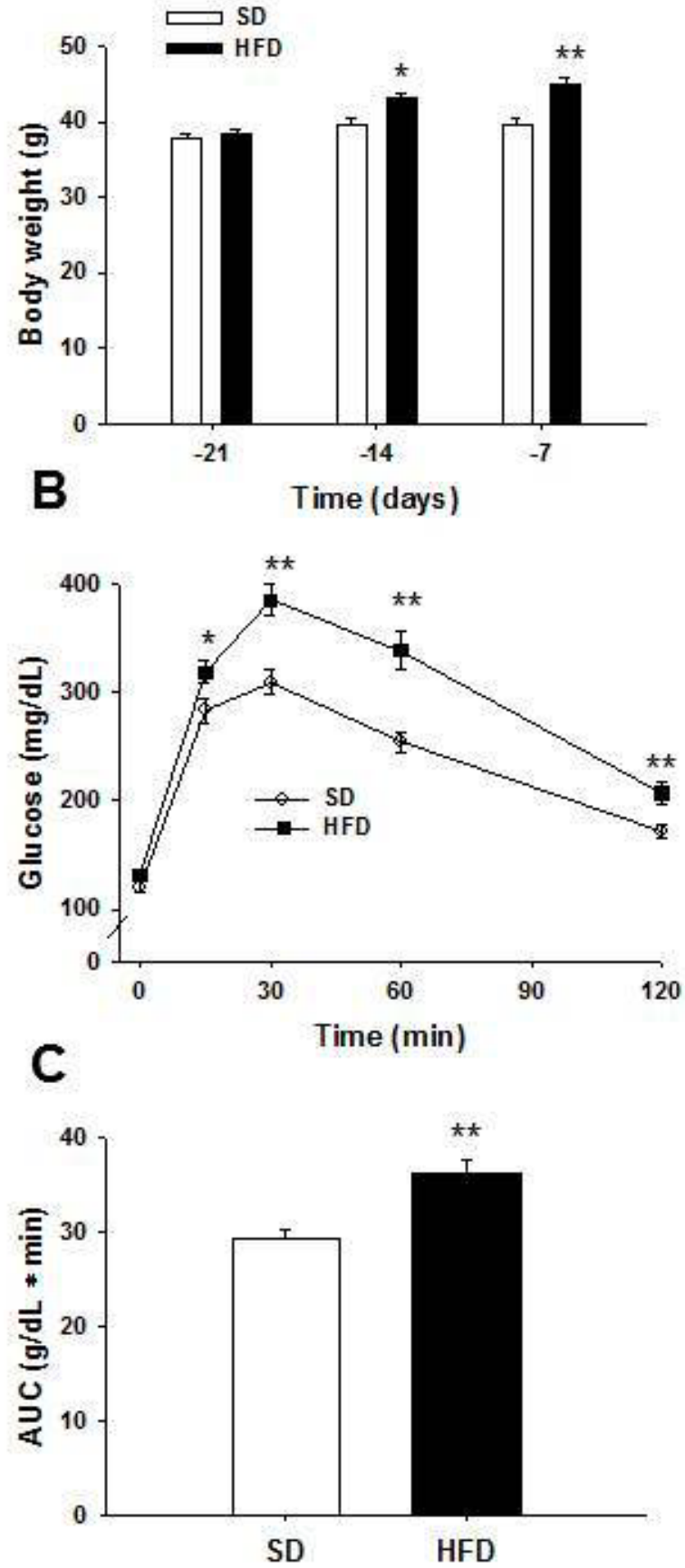

(A) There were no initial body weight differences when female ICR mice were placed on standard diet (SD) and high fat diet (HFD). After 7 and 14 days on the diets, females on the HFD had increased body weight compared to females fed the SD. A glucose tolerance test was performed after 2 weeks. (B) Female mice on the HFD had significantly increased blood glucose levels compared to females on the SD. (C) Area under the curve was significantly increased in females on the HFD compared to those on the SD. ${ }^{*} P<0.05$ and ${ }^{* *} P<0.01$ compared to $S D ; n=30$ for $S D$ and $n$ $=30$ for HFD in A - C. Error bars indicate s.e.m.

Figure 1: Two weeks on a high fat diet increases body weight and impairs glucose tolerance in female mice. 
A

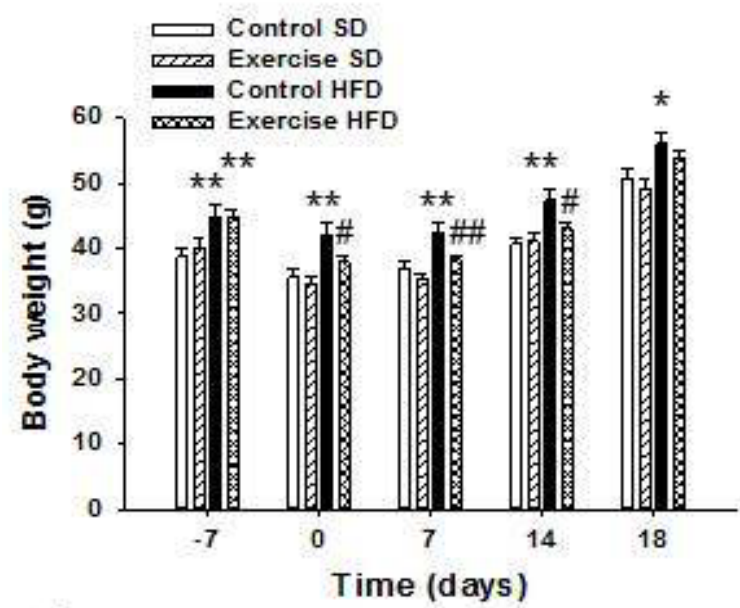

C

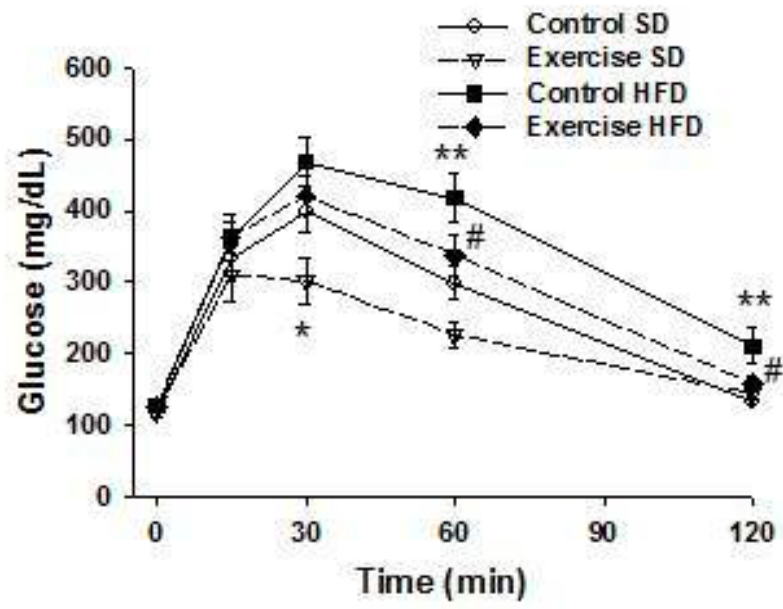

$\mathbf{B}$
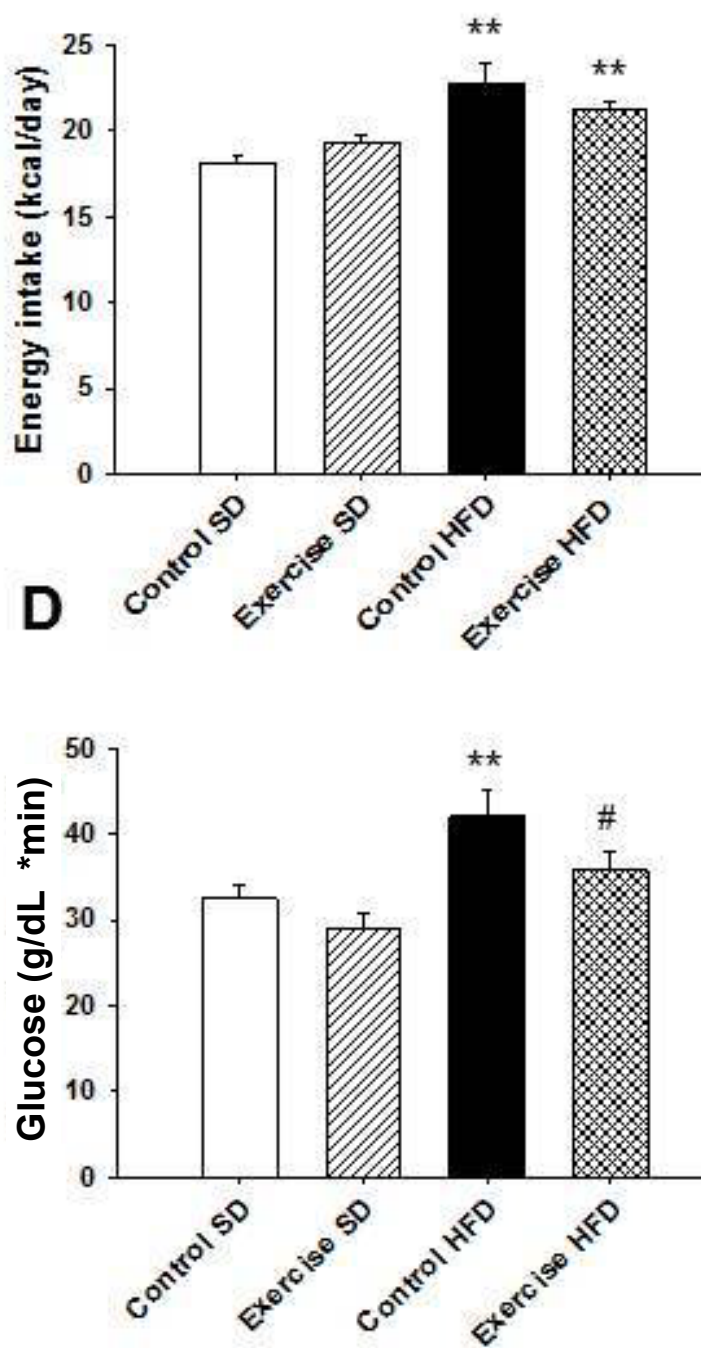

Female mice from (Figure 1) were split into control SD, exercise SD, control HFD, and exercise HFD groups. (A) Exercise HFD mice weighed significantly less than control HFD mice during mating and gestation. (B) Female mice on HFD had significantly increased daily energy intake compared to those on SD. (C) At mid-gestation, pregnant dams underwent glucose tolerance testing. Control dams on HFD had significantly higher blood glucose levels compared to control mice on the SD after glucose injection. Exercise significantly improved glucose disposal in HFD fed dams when compared to HFD fed control dams. (D) AUC was significantly increased in control HFD dams compared to SD dams, and exercise attenuated this increase. ${ }^{*} P<0.05$ and ${ }^{* *} P<0.01$ compared to control SD; \#P $<0.05$ and \#\#P $<0.01$ compared to control HFD; $n=11$ for control SD, $n=11$ for exercise SD, $n=12$ for control HFD, and $n=15$ for exercise HFD in A - D. Error bars indicate s.e.m.

Figure 2: Voluntary exercise decreases weight gain and improves glucose tolerance during pregnancy in female mice on a high fat diet.

were no significant differences in total lean mass between the groups (Figure 3A). Control dams on HFD had significantly increased fat mass compared to SD fed control dams $(\mathrm{P}<0.001)$ (Figure 3B). Exercise protected HFD fed dams against the increase in fat mass $(\mathrm{P}<0.001)$ such that fat mass was not significantly different than SD fed control dams. These data suggest that exercise during pregnancy can prevent increases in fat mass caused by HFD consumption.

\section{Adipose tissue and skeletal muscle Akt phosphorylation}

In order to assess whether glucose disposal was improved as a result of improved insulin signaling, basal and insulin stimulated phosphorylated Akt expression were analyzed in adipose and skeletal muscle isolated from dams late in pregnancy. Biochemical analysis focused on tissues from HFD fed dams since differences in glucose tolerance and body composition were most obvious in these two groups. No differences were observed in total Akt levels between the two groups. There were no differences in basal expression of phosphorylated Akt in adipose tissue between control and exercise HFD fed dams (Figure 4A). After insulin stimulation however, adipose tissue from exercise dams showed significantly increased levels of phosphorylated Akt compared to adipose from HFD fed controls $(\mathrm{P}=0.010)$ (Figure $4 \mathrm{~B})$. In addition, there were no significant differences between basal and insulin stimulated phosphorylated Akt in adipose tissue from control HFD dams. Adipose tissue from exercising HFD dams, however, showed a significant increase in phosphorylated Akt levels after insulin stimulation compared to basal phosphorylated Akt 
A

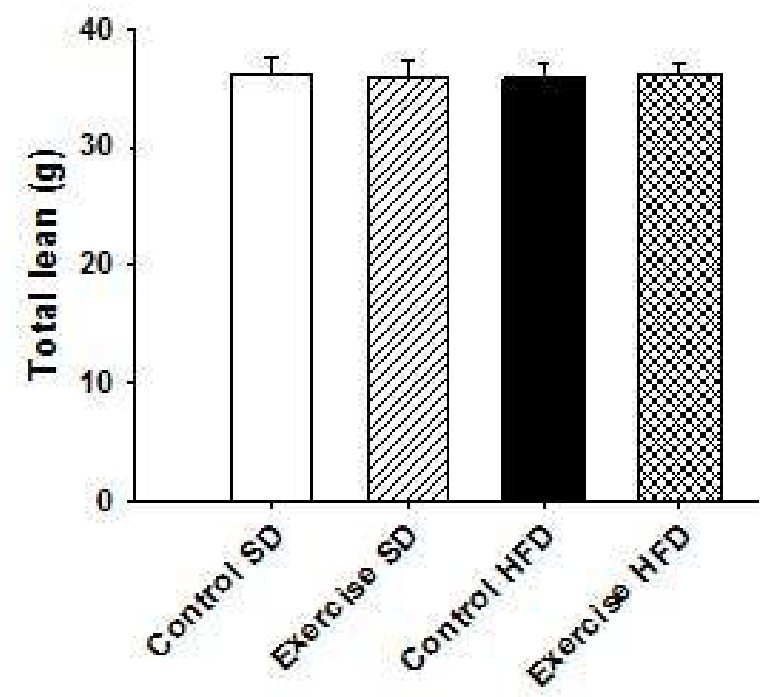

B

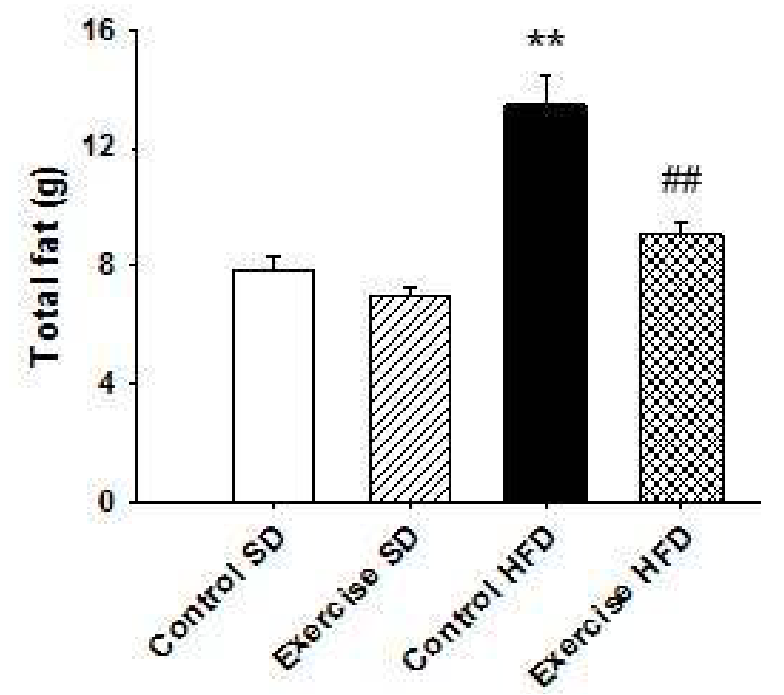

Late in pregnancy, body composition was analyzed in pregnant mice. (A) There were no differences in total lean mass between groups. (B) Fat mass was significantly increased in control dams on HFD compared to dams on $\mathrm{SD}$. Exercise significantly decreased fat mass in dams on HFD compared to control dams on HFD. ${ }^{* *} P<0.01$ compared to control SD; \#\# $<0.01$ compared to control HFD; $n=11$ for control SD, $n=11$ for exercise SD, $n=12$ for control HFD, and $n=15$ for exercise HFD in A - B. Error bars indicate s.e.m.

Figure 3: Voluntary exercise during pregnancy decreases fat mass in pregnant mice on a high fat diet.

levels $(\mathrm{P}=0.011)$. There were no differences in either basal (Figure $4 \mathrm{C})$ or insulin stimulated (Figure 4D) phosphorylated Akt expression in skeletal muscle from control and exercise dams on HFD. These data suggest that exercise during pregnancy improved insulin signaling in adipose tissue of HFD fed pregnant mice.

\section{Discussion}

This study demonstrates that voluntary exercise can improve glucose tolerance in HFD fed pregnant mice. We found that exercise during pregnancy was able to significantly increase insulin stimulated Akt phosphorylation in adipose tissue in exercising dams fed a HFD compared to control dams fed a HFD. This suggests that exercising HFD fed dams are more insulin sensitive than HFD fed controls. The observed decreases in fat mass in exercising dams on a HFD compared to HFD fed controls could contribute to adipose tissue insulin sensitivity. It is well known that fat accumulation can lead to insulin resistance [23]. As fat mass increases, macrophages accumulate within the adipose tissue and lead to a pro-inflammatory environment [24]. The adipose tissue releases numerous pro-inflammatory hormones and cyto/adipokines that can further decrease whole body insulin sensitivity [23] through inactivation of key proteins involved in the insulin signaling pathway in white adipose tissue and skeletal muscle [25]. Decreasing fat mass during pregnancy through physical activity could be critical to increasing insulin sensitivity, especially in women with diet induced obesity.

It is important to note that insulin independent glucose uptake most likely contributed to the increases in glucose uptake observed in the exercising dams. Contraction can stimulate glucose uptake in the absence of insulin. As muscles contract and energy is depleted, AMP activated protein kinase (AMPK) can be activated to stimulate glucose transporter type 4 translocation to the cellular surface to promote glucose uptake into muscle [26,27]. Future studies using this animal model will look at skeletal muscle expression and activation of AMPK and other proteins involved in insulin independent glucose transport.

High fat feeding has been shown to be a risk factor for developing glucose intolerance and GDM in animals and humans [16,28,29]. Previous studies pertaining to exercise during pregnancy, especially those focused on women at risk for developing GDM and those with GDM, have yielded conflicting results. Many have shown that exercise prior to pregnancy and during early pregnancy can reduce the risk of developing GDM while others have shown that physical activity can reduce the need for insulin to control blood glucose in women already diagnosed with GDM [18,19,30,31]. A recent randomized control trial has found however, that exercise during pregnancy did not reduce the risk of developing GDM [21]. These differing results support the need for the use of animal models to study exercise during pregnancy, especially those complicated by HFD consumption and GDM. Using a HFD diet in this study we induced a GDM-like state of impaired glucose tolerance in mice and furthered studied the protective effects of exercise. Though, it should be noted that the female mice were already glucose intolerant prior to pregnancy.

Diabetes during pregnancy is not only detrimental to the pregnant female, but can also lead to developmental programming of the offspring. Our model will be a useful tool to investigate interventions used to reverse the long-term offspring outcomes that result from maternal obesity. Previous animal studies have shown that high fat feeding during pregnancy and nursing can cause endothelial dysfunction, hypertension, impaired glucose tolerance and insulin resistance, as well as fatty liver in offspring [13,32-34]. Adiposity has also been shown to be increased in adult offspring from dams fed a high fat diet [35]. In humans, exposure to obesity and GDM in utero has been found to result in increased offspring incidence of diabetes and obesity in adolescence and adulthood [36,37]. Lesser studied are the effects of exercise during pregnancy and offspring health outcomes, especially in mothers who are obese or have gestational diabetes. 

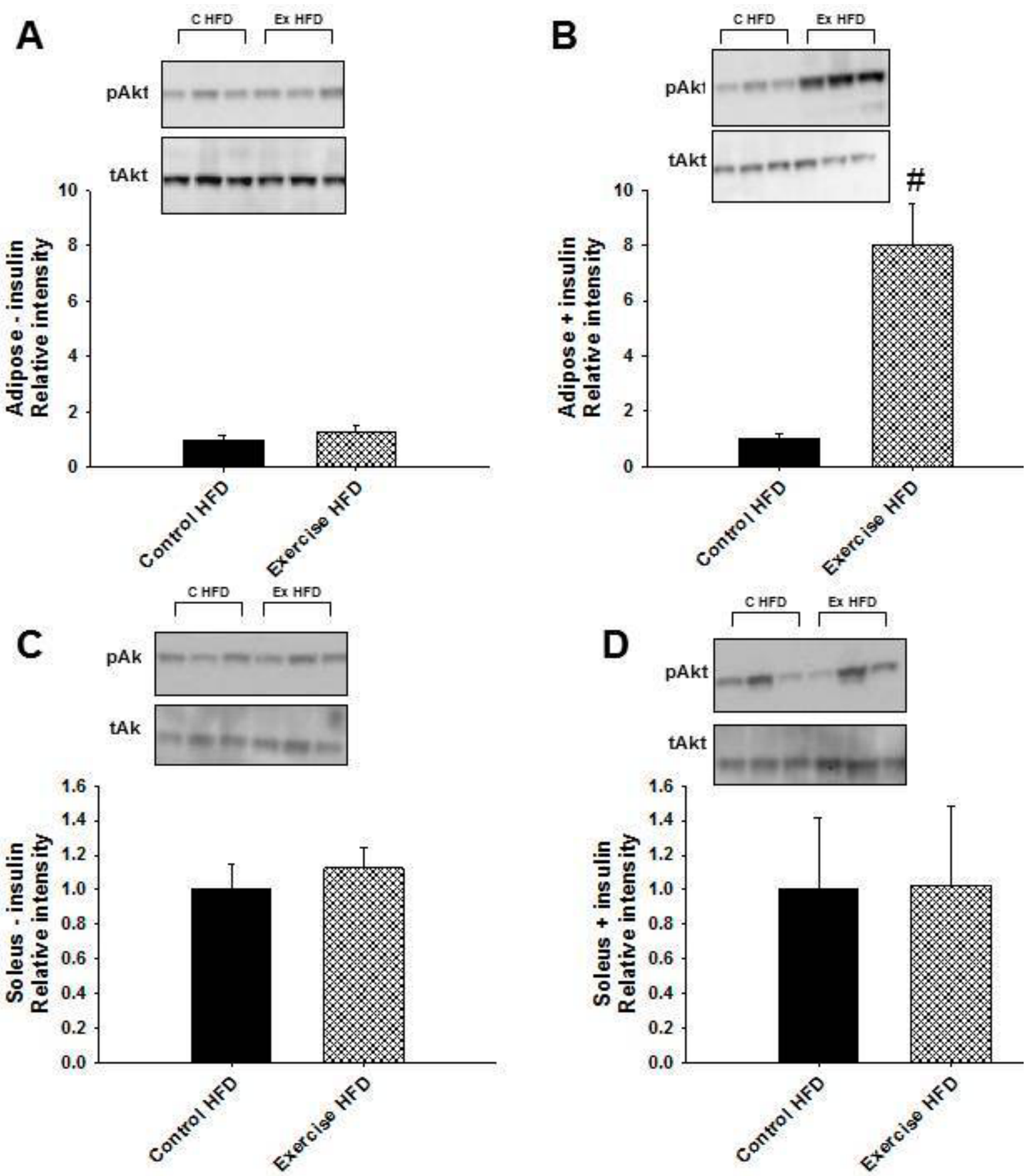

Late in pregnancy, mice were injected with saline or insulin, and tissues were collected for in vitro analyses. (A) There were no differences between groups in basal phosphorylated Akt levels in adipose tissue. (B) Following insulin stimulation, phosphorylated Akt adipose tissue levels were significantly increased in the exercise HFD dams compared to control HFD dams. There were no differences between the two groups in basal (C) or insulin stimulated (D) skeletal muscle levels of phosphorylated Akt. \#P $<0.05$ compared to control HFD; $n=3$ for control (c) HFD and $n=3$ for exercise (ex) HFD in A - D. Error bars indicate s.e.m.

Figure 4: Voluntary exercise during pregnancy increased insulin stimulated Akt phosphorylation in adipose tissue from mice on a high fat diet.

In healthy pregnancies, exercise has been found to decrease birth weight and adiposity [38]. Previously published data from our lab indicates that exercise during pregnancy can have long - term effects on offspring metabolism such that adult offspring from exercised dams show improved glucose tolerance as well as enhanced insulin sensitivity compared to offspring from control dams [39-40]. We are currently exploring controlled exercise as a maternal intervention as well [41]. Other laboratories have found similar benefits of perinatal exercise on glucose homeostasis or obesity-related phenotypes in the offspring [42-44]. Therefore, additional upcoming studies will also focus on how exercise can protect offspring from the harmful effects of high fat feeding and GDM during pregnancy and nursing. 
Several factors should be considered when reviewing these data. Given the mating scheme used in this study, it was impossible to time the exact day of conception and therefore we were unable to get accurate gestation ages at the termination of the experiment. Regardless, litter size was unaffected by maternal exercise, however there was a significant effect of diet when a two-way ANOVA was conducted such that HFD dams had significantly larger litter sizes than $\mathrm{SD}$ dams $(\mathrm{P}=0.023)$ (data not shown). Alternatives to this breeding approach would include using artificial insemination or timed mating so that the exact date of conception would be known. The amount of running observed when mice have voluntary access to a running wheel could be considered another limitation. The mice from this study ran up to $14 \mathrm{~km} /$ day which may not be realistic for translation to human studies. An alternative approach would be to use a controlled exercise model in which the mice are taken out of a home cage and placed into a running wheel for a predetermined amount of time per day. The controlled exercise model could also be used to determine the amount of physical activity required for maternal and offspring beneficial effects to be observed. Both the controlled and voluntary exercise model can be used to determine the stage of pregnancy or nursing that physical activity is most beneficial. This animal model provides important information on the effects of high fat feeding and exercise during pregnancy that is independent of the current limitations.

The findings from the present study, if translated to humans, could help promote the use of physical activity interventions for obese or atrisk pregnancies. The animal model used in this study could also be employed to further investigate the maternal and offspring effects and mechanisms of exercise during an unhealthy pregnancy.

\section{Acknowledgements}

This study was supported by US National Institutes of Health (NIH) grants (from The National Institute of Diabetes and Digestive and Kidney Diseases, R01 DK090460, and The National Institute of Environmental Health Sciences, P42 ES007380 to K.J.P.) and the research core of the COBRE on Obesity and Cardiovascular Diseases from the National Center for Research Resources (5P20 RR021954) and the National Institute of General Medical Sciences (8P20 GM103527). L.G.C. was supported by an NIH training grant (T32 DK07778).

\section{References}

1. Buchanan TA, Xiang A, Kjos SL, Watanabe R (2007) What is gestational diabetes? Diabetes Care 30: S105-111.

2. CDC (2008) Centers for Disease Control and Prevention. National diabetes fact sheet: general information and national estimates on diabetes in the United States, 2007. Atlanta, GA: U.S. Department of Health and Human Services, Centers for Disease Control and Prevention.

3. Dabelea D, Snell-Bergeon JK, Hartsfield CL, Bischoff KJ, Hamman RF, et al. (2005) Increasing prevalence of gestational diabetes mellitus (GDM) over time and by birth cohort: Kaiser Permanente of Colorado GDM Screening Program. Diabetes Care 28: 579-584

4. Lawrence JM, Contreras R, Chen W, Sacks DA (2008) Trends in the prevalence of preexisting diabetes and gestational diabetes mellitus among a racially/ ethnically diverse population of pregnant women, 1999-2005. Diabetes Care 31: 899-904

5. Artal R (2003) Exercise: the alternative therapeutic intervention for gestational diabetes. Clin Obstet Gynecol 46: 479-487.

6. Metzger BE, Buchanan TA, Coustan DR, de Leiva A, Dunger DB, et al. (2007) Summary and recommendations of the Fifth International WorkshopConference on Gestational Diabetes Mellitus. Diabetes Care 30: S251-260.

7. Pettitt DJ, Nelson RG, Saad MF, Bennett PH, Knowler WC (1993) Diabetes and obesity in the offspring of Pima Indian women with diabetes during pregnancy. Diabetes Care 16: 310-314

8. Franks PW, Looker HC, Kobes S, Touger L, Tataranni PA, et al. (2006) Gestational glucose tolerance and risk of type 2 diabetes in young Pima Indian offspring. Diabetes 55: 460-465.
9. Bush NC, Chandler-Laney PC, Rouse DJ, Granger WM, Oster RA, et al. (2011) Higher Maternal Gestational Glucose Concentration Is Associated with Lower Offspring Insulin Sensitivity and Altered \{beta\}-Cell Function. J Clin Endocrinol Metab 96: E803-809.

10. Boloker J, Gertz SJ, Simmons RA (2002) Gestational diabetes leads to the development of diabetes in adulthood in the rat. Diabetes 51: 1499-1506.

11. Guo F, Jen KL (1995) High-fat feeding during pregnancy and lactation affects offspring metabolism in rats. Physiol Behav 57: 681-686.

12. Plagemann A, Harder T, Rake A, Voits M, Fink H, et al. (1999) Perinatal elevation of hypothalamic insulin, acquired malformation of hypothalamic galaninergic neurons, and syndrome x-like alterations in adulthood of neonatally overfed rats. Brain Res 836: 146-155.

13. Taylor PD, McConnell J, Khan IY, Holemans K, Lawrence KM, et al. (2005) Impaired glucose homeostasis and mitochondrial abnormalities in offspring of rats fed a fat-rich diet in pregnancy. Am J Physiol Regul Integr Comp Physio 288: R134-139.

14. Harris SB, Caulfield LE, Sugamori ME, Whalen EA, Henning B (1997) The epidemiology of diabetes in pregnant Native Canadians. A risk profile. Diabetes Care 20: 1422-1425.

15. Dornhorst A, Rossi M (1998) Risk and prevention of type 2 diabetes in women with gestational diabetes. Diabetes Care 21: B43-49.

16. Chu SY, Callaghan WM, Kim SY, Schmid CH, Lau J, et al. (2007) Maternal obesity and risk of gestational diabetes mellitus. Diabetes Care 30: 2070-2076.

17. Jovanovic $L$ (2001) What is so bad about a big baby? Diabetes Care 24: 1317 1318.

18. Liu J, Laditka JN, Mayer-Davis EJ, Pate RR (2008) Does physical activity during pregnancy reduce the risk of gestational diabetes among previously inactive women? Birth 35: 188-195.

19. Brankston GN, Mitchell BF, Ryan EA, Okun NB (2004) Resistance exercise decreases the need for insulin in overweight women with gestational diabetes mellitus. Am J Obstet Gynecol 190: 188-193.

20. de Barros MC, Lopes MA, Francisco RP, Sapienza AD, Zugaib M (2010) Resistance exercise and glycemic control in women with gestational diabetes mellitus. Am J Obstet Gynecol 203: 556.

21. Stafne SN, Salvesen KÅ, Romundstad PR, Eggebø TM, Carlsen SM, et al. (2012) Regular exercise during pregnancy to prevent gestational diabetes: a randomized controlled trial. Obstet Gynecol 119: 29-36.

22. Hopkins SA, Baldi JC, Cutfield WS, McCowan L, Hofman PL (2010) Exercise training in pregnancy reduces offspring size without changes in maternal insulin sensitivity. J Clin Endocrinol Metab 95: 2080-2088.

23. Kahn SE, Hull RL, Utzschneider KM (2006) Mechanisms linking obesity to insulin resistance and type 2 diabetes. Nature 444: 840-846.

24. Weisberg SP, McCann D, Desai M, Rosenbaum M, Leibel RL, et al. (2003) Obesity is associated with macrophage accumulation in adipose tissue. $J$ Clin Invest 112: 1796-1808.

25. Kahn BB, Flier JS (2000) Obesity and insulin resistance. J Clin Invest 106 473-481.

26. Tullson PC, Terjung RL (1990) Adenine nucleotide degradation in striated muscle. Int J Sports Med 11: S47-55.

27. Tullson PC, Whitlock DM, Terjung RL (1990) Adenine nucleotide degradation in slow-twitch red muscle. Am J Physiol 258: C258-265.

28. Xiong X, Saunders LD, Wang FL, Demianczuk NN (2001) Gestational diabetes mellitus: prevalence, risk factors, maternal and infant outcomes. Int J Gynaecol Obstet 75: 221-228.

29. Liang C, DeCourcy K, Prater MR (2010) High-saturated-fat diet induces gestational diabetes and placental vasculopathy in C57BL/6 mice. Metabolism 59: 943-950.

30. Tobias DK, Zhang C, van Dam RM, Bowers K, Hu FB (2011) Physical activity before and during pregnancy and risk of gestational diabetes mellitus: a metaanalysis. Diabetes Care 34: 223-229.

31. Harizopoulou VC, Kritikos A, Papanikolaou Z, Saranti E, Vavilis D, et al. (2010) Maternal physical activity before and during early pregnancy as a risk factor for gestational diabetes mellitus. Acta Diabetol 47: 83-89. 
Citation: Carter LG, Tenlep SYN, Woollett LA, Pearson KJ (2015) Exercise Improves Glucose Disposal and Insulin Signaling in Pregnant Mice Fed a High Fat Diet. J Diabetes Metab 6: 634. doi:10.4172/2155-6156.1000634

Page 8 of 8

32. Khan IY, Dekou V, Douglas G, Jensen R, Hanson MA, et al. (2005) A highfat diet during rat pregnancy or suckling induces cardiovascular dysfunction in adult offspring. Am J Physiol Regul Integr Comp Physiol 288: R127-133.

33. Ashino NG, Saito KN, Souza FD, Nakutz FS, Roman EA, et al. (2012) Maternal high-fat feeding through pregnancy and lactation predisposes mouse offspring to molecular insulin resistance and fatty liver. J Nutr Biochem 23: 341-348.

34. Elahi MM, Cagampang FR, Mukhtar D, Anthony FW, Ohri SK, et al. (2009) Long-term maternal high-fat feeding from weaning through pregnancy and lactation predisposes offspring to hypertension, raised plasma lipids and fatty liver in mice. Br J Nutr 102: 514-519.

35. Samuelsson AM, Matthews PA, Argenton M, Christie MR, McConnell JM, et al. (2008) Diet-induced obesity in female mice leads to offspring hyperphagia, adiposity, hypertension, and insulin resistance: a novel murine model of developmental programming. Hypertension 51: 383-392.

36. Dabelea D, Hanson RL, Lindsay RS, Pettitt DJ, Imperatore G, et al. (2000) Intrauterine exposure to diabetes conveys risks for type 2 diabetes and obesity: a study of discordant sibships. Diabetes 49: 2208-2211.

37. Dabelea D (2007) The predisposition to obesity and diabetes in offspring of diabetic mothers. Diabetes Care 30: S169-174.

38. Clapp JF (1996) Morphometric and neurodevelopmental outcome at age five years of the offspring of women who continued to exercise regularly throughout pregnancy. J Pediatr 129: 856-863.

39. Carter LG, Lewis KN, Wilkerson DC, Tobia CM, Ngo Tenlep SY, et al. (2012) Perinatal exercise improves glucose homeostasis in adult offspring. Am J Physiol Endocrinol Metab 303: E1061-1068.

40. Carter LG, Qi NR, De Cabo R, Pearson KJ (2013) Maternal exercise improves insulin sensitivity in mature rat offspring. Med Sci Sports Exerc 45: 832-840.

41. Platt KM, Charnigo RJ, Kincer JF, Dickens BJ, Pearson KJ (2013) Controlled exercise is a safe pregnancy intervention in mice. J Am Assoc Lab Anim Sci 52: $524-530$.

42. Vega C, Reyes-Castro LA, Bautista CJ, Larrea F, Nathanielsz PW, et al. (2015) Exercise in obese female rats has beneficial effects on maternal and male and female offspring metabolism. Int J Obes (Lond) 39: 712-719.

43. Laker RC, Lillard TS, Okutsu M, Zhang M, Hoehn KL, et al. (2014) Exercise prevents maternal high-fat diet-induced hypermethylation of the Pgc-1alpha gene and age-dependent metabolic dysfunction in the offspring. Diabetes 63 1605-1611.

44. Stanford KI, Lee MY, Getchell KM, So K, Hirshman MF, et al. (2015) Exercise before and during pregnancy prevents the deleterious effects of maternal highfat feeding on metabolic health of male offspring. Diabetes 64: 427-433. 